\title{
Evaluation of the Relationship between Organizational Culture and Job Motivation in Office Employees of Education and Development Department of the Counties of Semnan in the 2014-2015 Academic Year
}

\author{
Dr. Forouzan Zarabian \\ Assistant professor, Department of Educational Sciences, Payamenoor, University \\ PO Box 19395 -3697Theran, Iran; fzarabian@yahoo.com \\ Dr. Tayebeh Safaei \\ Assistant professor, Department of Educational Sciences, Payamenoor, University \\ PO Box 19395 -3697Theran, Iran; T_safaee@yahoo.com \\ Soghra Sadeghi \\ MA student of Education Management, Payamenoor, University, SouthTehran, Iran \\ Department of Education,Semnan, Iran; s.sadeghi1391@yahoo.com
}

\section{Doi:10.5901/mjss.2016.v7n2s2p35}

\section{Abstract}

\begin{abstract}
The main purpose of this research was evaluation of the relationship between organizational culture and job motivation of office employees of education and development department of the province of Semnan. Statistical population of this research included all office employees of education and development department of the counties of Semnan in the 2014-2015 academic year who according to the latest statistical information from the main provincial office for Semnan are 300 individuals. From among the statistical population of the research, 150 individuals were selected by simple sampling (based on personnel number and random selection from table of random numbers) based on the Kerjcie Morgan table. For measurement of variables questionnaires of organizational culture by Moghimi (2011) job motivation by Halkman and Oldheim (1980) were used. Results showed that correlation exists between organizational culture and job motivation in office workers of education and development department of the counties of Semnan in the 1994-1995 academic year. The situation for organizational culture and job motivation among employees of the education and development offices of the counties of Semnan was above average. Correlation existed between constituents of organizational culture (job challenges, communication, innovation, trust, social cohesiveness) of employees with their job motivation in education and department offices of the counties of Semnan. Correlation existed between constituents of job motivation (skills' variety, value of duty, supervisor feedback, meaningfulness of duty, independence) with organizational culture in employees of education and development department of the counties of Semnan.
\end{abstract}

Keywords: Organizational Culture, Job Motivation, Job Challenges, Value of Duty, Employee Social Connectedness

\section{Introduction and Statement of Problem}

«Organizational culture» is one of the most novel terms used in management literature that has gained the attention of management scientists and experts in recent years. With regards to organizational culture, researchers believe that the relationship of culture with an organization is similar to the relationship of personality with a person. They believe that for society's individuals to blossom, investigation is necessary with regards to their personality. On this basis, for blossoming of organizations which helps society blossom, research is needed regarding organizational culture.

In the opinion of Schein (2004), culture increases a social system's cohesiveness and leads to improved understanding of individuals and their behavior. What has been mentioned shows the fact that acceptance of culture and observance of sub structural principles and rules by the organization is not only part of duties, but also a guarantee for the corporation's sustenance and dynamicism. Organizational culture affects all aspects of an enterprise. Studies and research show that culture influences formulation of individual behavioral goals and strategies and employee performance, motivation and job satisfaction, creativity and innovation and method of decision making as well as level of employee participation in matters and etc (Amirkabiri \& Tehrani, 2006). 


\section{Job Motivation}

The basis of motivation is a force that advances a human being towards provision of needs, realization of wishes and creation of tendencies that determine new behavior and consequently leads to a state of balance in the person. This term in its modern day meaning refers to psychological processes that stimulate, guide and follow through with voluntary actions and activities directed towards achieving job objectives (Motlaghi, 2014).

Job Challenge: is defined as stresses and problems arising from job dissatisfaction.

Job Value: it is the value of a job that determines a given individual's work and occupation.

Employee Social Cohesion: Parson's defines employee social cohesion as cohesion, unification and connectedness in occupational systems.

Interest with will to perform a task or motivation is the main factor leading to efforts and actions in the individual or individuals. Motivation is one of the important tools in inducing employees into production of effective and efficient results, creation of positive work environment and successful implementation of predicted plans. Education and development employees form the main trunk of this organization and undoubtedly are more important in the system than programs, activities, equipment and materials. Education and development departments need motivated employees as one of their pillars for training and educating so they can be effective and teaching and promoting society's psychological health and preventing the creation of an ill and nonproductive society in the future.

Now a day, considering the overall changes and evolution in organizations, evaluation of factors influential on employee motivation is a necessity. In other words, growth, scientific and technical progress and increased complexity in the working world have led evaluation of factors effective on motivation to become increasingly important. The reason is that employee motivation is correlated with their efficiency. Under conditions that an individual lacks any motivation for working, even if he or she performs a duty, it is with lack of interest and forceful and only for executing a higher officials orders. Under these conditions, identification of job motivation factors in the organization can increase employee efficiency and turn the work environment into a joyful one.

\section{Background}

Belias (2014) and colleagues in a research evaluated the relationship between organizational culture and job satisfaction and reported in their results that promotion of elements of organizational culture can significantly lead to increased job satisfaction and these variables have positive and meaningful correlation with each other.

Owoyemi (2014) in a research evaluated organizational culture as a tool for control of the enterprise on employees of various organizations. In their results, they reported that elements of organizational culture have positive and meaningful correlation with better enterprise control and organizational culture can increase control over various factors in the enterprise.

Davoudi (2013) evaluated organizational culture and job motivation with work satisfaction in teachers with participation of a sample of 200 teachers in the county of Trisergan and the results have shown that the variables of job motivation, organizational culture and age are meaningful predictors of work satisfaction. The constituents of job motivation compared to constituents of organizational culture were meaningful predicting variables for work satisfaction.

Hossein Zeinalipour and colleagues (2014) in a research evaluated the relationship between organizational culture and work satisfaction with participation of 371 teachers and reported in their results that elements of organizational culture had the highest percent of meaningful correlation with elements of work satisfaction.

Marlin El (2010) also in a research titled "Effect of motivation on work satisfaction of nursing managers" showed that: directors who had long history in executive management and had great collaboration with nursing universities and schools showed direct correlation between their job motivation and satisfaction. Additionally, motivation was an important predictor of work satisfaction. Also, Jolia Skooler and colleagues (2010) in a research titled "Relationship between work satisfaction and job motivation" found out that job motivation has positive effect on work satisfaction.

Considering the research mentioned above, it still appears that necessity for investigation of this important topic remains. Additionally in Iran cohesive and comprehensive research regarding the relationship between variables of organizational culture and job motivation has not been performed. Therefore, this research was performed with the purpose of responding to the question that is there a correlation between job motivation and organizational culture? And is organizational culture a reliable predictor for job motivation in education and development employees? 


\section{Research Questions}

1- Is there a relationship between organizational culture and job motivation in education and development employees of the counties of Semnan in the 2014-2015 academic year?

2- What is the situation of organizational culture among education and development employees of the counties of Semnan?

3- What is the situation of motivation among education and development employees in the counties of Semnan?

4- Is there a relationship between constituents of organizational culture (job challenge, communication, innovation, trust and social connectedness) with job motivation among education and development employees of the counties of Semnan?

5- Is there a relationship between constituents of job motivation (skills' diversity, value of duty, and feedback from supervisor, meaningful duties and independence) with organizational culture among education and development employees of the counties of Semnan?

6- Is there relationship between organizational culture with motivation and work experience of education and development employees in the counties of Semnan?

\section{Method}

The method of research regarding collection of descriptive data was correlational and descriptive (non experimental). The statistical population of this research included all employees of education and development offices in the counties of Semnan province in the 2014-2015 academic year, where according to lasts statistics by the general office of province of Semnan are 300 individuals. From among the statistical population, a number of 150 individuals were selected by simple sampling (based on personnel number and random selection from table of random numbers) and based on the Kerjcie Morgan table.

\section{Measurement Instruments}

Organizational Culture Questionnaire: This questionnaire was presented by Lorsh for evaluation of entrepreneurial organizational culture. This questionnaire has been translated and shortened by Moghimi (1390) and has been designed in the frame of four main groups. This questionnaire has 18 items scored based on a 5-point Likert scale (completely disagree, 1; disagree, 2; undecided, 3; agree, 4; completely agree, 5). A higher score shows higher organizational culture and that the organization possesses higher entrepreneurial culture. It consists of 5 constituents: job challenge, communication, innovation, trust and social cohesiveness. The validity and reliability of this questionnaire has been confirmed in many studies in the past. The questionnaire validity with consideration of opinions of respected university professors and experts has been confirmed. In Iran, the Cronbach's alpha coefficient for this questionnaire has been reported above 0/7 (Isfehani, 2012). Additionally, Hassani and colleagues (2012) have reported a reliability for this questionnaire of $0 / 75$.

Job Motivation Questionnaire: The purpose of this questionnaire is evaluation of organizational employee outlooks and various dimensions (skills' diversity, job identity, job value, independence and feedback) and it was formulated by Halkman and Oldheim (1980). This questionnaire is scored by a 5-point Likert scale with scores of 4 for the first choice, 3 for the second choice, 2 for the third choice and the last choice had a score of 1.

It has five main nuclei identified for work dimensions: skills' diversity, job identity, job value, independence and feedback. The validity of the questionnaire has been confirmed by respectable university professors and also in the study by Ghamari and colleagues (2012), the validity of the questionnaire has been confirmed and its reliability considering the Cronbach's alpha coefficient has been reported at 0/63.

\section{Method of Data Analysis}

After collection of the questionnaires from respondents and controlling them, for the purpose of data analysis the SPSS version 22 statistical software package was used. In the descriptive statistics section, table for distribution, graphs, central tendency measures and measures of dispersion and ... were taken advantage of. In the section on hypotheses evaluation simple and multivariate correlation coefficients, t-test for independent groups and step by step regression analysis were used. 


\section{Results}

Using descriptive statistics, the scale for organizational culture and its subscales were evaluated (Table 1).

Table 1. Descriptive statistics, scale and subscales of organizational culture

\begin{tabular}{|l|l|c|c|c|c|c|}
\hline Variables & Subscales & Number of items & Mean & Standard deviation & Minimum & Maximum \\
\hline \multirow{5}{*}{ Job motivation } & Motivation & 10 & $28 / 21$ & $6 / 53$ & 12 & 42 \\
\cline { 2 - 7 } & Skills & 2 & $6 / 43$ & $1 / 35$ & 3 & 8 \\
\cline { 2 - 7 } & Duties & 2 & $5 / 64$ & $1 / 83$ & 2 & 8 \\
\cline { 2 - 7 } & Supervisor feedback & 2 & $5 / 79$ & $2 / 32$ & 2 & 24 \\
\cline { 2 - 7 } & Meaningful duty & 2 & $5 / 53$ & $1 / 78$ & 2 & 8 \\
\cline { 2 - 7 } & Independence & 2 & $5 / 64$ & $1 / 83$ & 2 & 8 \\
\hline \multirow{5}{*}{ Organizational culture } & Organizational culture & 18 & $64 / 54$ & $14 / 49$ & 32 & 90 \\
\cline { 2 - 7 } & Job challenge & 5 & $21 / 13$ & $6 / 16$ & 5 & 62 \\
\cline { 2 - 7 } & Communication & 4 & $14 / 59$ & $6 / 30$ & 5 & 57 \\
\cline { 2 - 7 } & Innovation & 4 & $14 / 02$ & $6 / 58$ & 4 & 57 \\
\cline { 2 - 7 } & Trust & 3 & $10 / 44$ & $3 / 02$ & 3 & 15 \\
\cline { 2 - 7 } & Social cohesiveness & 2 & $7 / 02$ & $2 / 58$ & 2 & 24 \\
\hline
\end{tabular}

Mean for subscales of job motivation: skills, duty, supervisor feedback, meaningful duty, independence and job motivation scale were $6 / 43,5 / 64,5 / 79,5 / 53,5 / 64,28 / 21$ respectively. Based on the questionnaire guideline, a higher score on the scale in each of the subscales shows higher job motivation.

Mean for subscales of organizational culture: job challenge, communication, innovation, trust, social cohesiveness and organizational culture scale were 21/13, 14/59, 14/02, 10/44, 7/02 and 64/54 respectively.

\section{Research Questions}

1- Is there a relationship between organizational culture and job motivation in education and development employees of the counties of Semnan in the 2014-2015 academic year?

Table 2. Matrix for correlation coefficients, organizational culture and job motivation

\begin{tabular}{|l|c|c|}
\hline \hline Variable & 1 & 2 \\
\cline { 1 - 2 } & Job motivation scale & 1 \\
\cline { 2 - 3 } & Organizational culture scale & \multirow{2}{*}{1} \\
\hline \hline $0 / 01 *: p$ value $<0 / 05$ & $0 / 45^{\star *}$ &
\end{tabular}

Meaningful correlation exists between job motivation and organizational culture of education and development employees in the counties of Semnan (correlation coefficient: 0/45, Pvalue $<0 / 01$ ). Therefore, it can be expected that with increased organizational culture, employee motivation increases and the reverse. Determining coefficient shows that 20 percent of the variance of job motivation can be explained by organizational culture. Additionally, it can be expected that with every unit increase in organizational culture, a level of $0 / 45$ is added to job motivation of education and development employees of the counties of Semnan.

2- What is the situation of organizational culture among education and development employees of the counties of Semnan?

For this hypothesis, a single group t-test was used.

Table 3. Statistics for single group t-test

\begin{tabular}{|c|c|c|c|c|c|c|}
\hline \hline & Mean & Standard deviation & T value & Degrees of freedom & Significance level & Mean differences \\
\hline Organizational culture & $64 / 54$ & $14 / 49$ & $8 / 85$ & 147 & $0 / 000$ & $10 / 54$ \\
\hline \hline
\end{tabular}

The organizational culture scale has 18 items that have been scored based on a 5-degree scale. Maximum score is 90 
and minimum can be 18. The theoretical mean for the organizational culture scale is 54 which are considered as a criterion for appropriateness of organizational culture.

Meaningful difference exists between mean organizational culture of education and development employees and 54 (theoretical mean) (Pvalue<0/01). Mean organizational culture of employees is 10/54 points higher than the theoretical criterion (54). Therefore, with 99 percent confidence it can be stated that the situation of organizational culture among employees of education and development offices of the counties of Semnan is higher than average. It should be noted that the mentioned criteria can be an index other than the mean.

3- What is the situation of motivation among education and development employees in the counties of Semnan?

Table 4. Statistics for single group t-test

\begin{tabular}{|c|c|c|c|c|c|c|}
\hline \hline & Mean & Standard deviation & T value & Degrees of freedom & Significance level & Mean differences \\
\hline Job motivation & $28 / 21$ & $6 / 53$ & $6 / 02$ & 149 & $0 / 000$ & $3 / 21$ \\
\hline \hline
\end{tabular}

Job motivation scale has 10 items which are scored based on a 4-degree Likert scale. The maximum score for this scale is 40 and the minimum is 10 . Theoretical mean for the organizational culture scale is 25 which has been considered as the appropriate criterion for organizational motivation. Between mean job motivation of education and department employees and 25 (theoretical mean), meaningful difference exists (Pvalue $<0 / 01)$. Mean job motivation of employees is $3 / 21$ points higher than the theoretical case (25). Therefore, with 99 percent confidence it can be stated that the situation of job motivation among employees of education and development offices of the counties of Semnan is higher than average.

4- Is there a relationship between constituents of organizational culture (job challenge, communication, innovation, trust and social connectedness) with job motivation among education and development employees of the counties of Semnan?

Table 5. Matrix for correlation coefficients, job stress and constituents of organizational culture

\begin{tabular}{|c|c|c|c|c|c|}
\hline Variable & 1 & 2 & 3 & 4 & 5 \\
\hline Job challenge & 1 & & & & \\
\hline Communication & $0 / 18^{*}$ & 1 & & & \\
\hline Innovation & $0 / 12$ & $0 / 91^{\star \star}$ & 1 & & \\
\hline Trust & $0 / 21^{\star *}$ & $0 / 48^{\star \star}$ & $0 / 55^{\star \star}$ & 1 & \\
\hline Social cohesion & $0 / 22^{\star *}$ & $0 / 33^{\star \star}$ & $0 / 36^{\star \star}$ & $0 / 68^{* *}$ & \\
\hline Job motivation & $0 / 19^{*}$ & $0 / 33^{* \star}$ & $0 / 31^{* *}$ & $0 / 43^{\star \star}$ & $0 / 31^{\text {** }}$ \\
\hline
\end{tabular}

**.p value $<0 / 01 *$ : $p$ value $<0 / 05$

Between job motivation and constituents of organizational culture meaningful correlation (Pvalue $<0 / 05$ ) exists with the following coefficients: job challenge, communication, innovation, trust, social cohesion 0/19, 0/33, 0/31, 0/43 and 0/31 respectively. Therefore, it can be expected that with increase in any of the constituents of organizational culture, job motivation increases in employees of offices of education and development in the counties of Semnan and the reverse. The multivariate correlation coefficient is $0 / 43$ and determination coefficient is 19 percent. Therefore, it can be stated that the constituents of organizational culture explain 19 percent of the variance of job motivation. In other words, 19 percent of elements of organizational culture and job motivation overlap with each other.

5- Is there a relationship between constituents of job motivation (skills' diversity, value of duty, and feedback from supervisor, meaningful duties and independence) with organizational culture among education and development employees of the counties of Semnan?

Table 6. Matrix for correlation coefficients

\begin{tabular}{|l|c|c|c|c|c|}
\hline \hline Variable & 1 & 2 & 3 & 4 & 5 \\
\hline Skills diversity & 1 & & & & \\
\hline Duties & $0 / 48^{\star \star}$ & 1 & & & \\
\hline Supervisor feedback & $0 / 36^{\star \star}$ & $0 / 58^{\star \star}$ & 1 & & \\
\hline Meaningful duty & $0 / 57^{\star \star}$ & $0 / 87^{\star *}$ & $0 / 57^{\star *}$ & 1 & \\
\hline
\end{tabular}




\begin{tabular}{|l|c|c|c|c|c|}
\hline Independence & $0 / 48^{* *}$ & $1^{* *}$ & $0 / 58^{\star *}$ & $0 / 87^{\star *}$ & 1 \\
\hline Organizational culture & $0 / 38^{* *}$ & $0 / 49^{\star *}$ & $0 / 36^{* *}$ & $0 / 52^{\star *}$ & $0 / 49^{\star *}$ \\
\hline
\end{tabular}

**:p value $<0 / 01 \quad *$ : $p$ value $<0 / 05$

Meaningful correlation exists between organizational culture and constituents of job motivation (Pvalue<0/01) with following correlation coefficients: skills diversity, duty, supervisor feedback, meaningful duty and independence of 0/38, $0 / 49,0 / 36,0 / 52$ and 0/49 respectively. Therefore, it can be expected that with increased organizational culture, all constituents of job motivation in employees of offices of education and development of the counties of Semnan increase and the reverse.

6- Is there relationship between organizational culture with motivation and work experience of education and development employees in the counties of Semnan?

Table 7. Model summary

\begin{tabular}{ccc}
\hline$R$ & $R^{2}$ & $R^{2}{ }_{\text {adj }}$ \\
\hline $0 / 45$ & $0 / 21$ & $0 / 20$ \\
\hline \hline
\end{tabular}

Multivariate correlation coefficient between the criterion variable (job motivation) and predicting variables (organizational culture and job experience) was 0/45 and moderated determination coefficient was 20 percent.

Table 8. Analysis of variance

\begin{tabular}{|l|c|c|c|c|c|}
\hline Source of variance & Sum of squares & Degrees of freedom & Mean squares & $F$ & Significance level \\
\hline Regression & $1293 / 23$ & 1 & $1293 / 23$ & & \multirow{2}{*}{$0 / 000$} \\
\hline Remainder & $5018 / 77$ & 142 & $35 / 43$ & $36 / 59$ & \multirow{2}{*}{ Total } \\
\hline
\end{tabular}

Considering $(F 1,142=36 / 59$, Pvalue $<0 / 01)$, it can be stated that the regression model selected for evaluation of the hypothesis under consideration is valid.

Table 9. Regression table

\begin{tabular}{|l|c|c|c|c|c|}
\hline \hline & Unstandardized coefficients & Standardized coefficients & t value & Significance level \\
\cline { 2 - 6 } & $\mathrm{b}$ coefficient & Standard error & $\beta$ coefficient & & \\
\hline Width from origin & $14 / 84$ & $2 / 25$ & --- & $6 / 57$ & $0 / 000$ \\
Organizational culture & $0 / 207$ & $0 / 034$ & $0 / 453$ & $6 / 04$ & $0 / 000$ \\
\hline \hline
\end{tabular}

Under the influence of organizational culture, the variable of work experience was removed from the regression.

\section{Regression Equation with Standard Coefficients}

\subsection{Organizational Culture 0/453=Y (Job Motivation)}

With every unit increase in organizational culture, job motivation in employees of offices of education and development of the counties of the province of Semnan increases by a 0/453 level.

\section{Conclusion}

1- Is there a relationship between organizational culture and job motivation in education and development employees of the counties of Semnan in the 2014-2015 academic year?

Results showed that meaningful correlation exists between job motivation and organizational culture in employees of offices of education and development of the counties of Semnan. These results agree with the findings reported by Marcoulided and Heck (2009) who in their studies in the context of organizational culture and performance and motivation have noted that organizational culture refers to a collection of value systems 
of an organization and common beliefs and opinions of members of the firm and personal values and beliefs. Organizational culture forms by way of structure and goals, values and duties of the firm, atmosphere, values and personal beliefs with the assumption that the mentioned factors are influential on organizational performance. Therefore, awareness of various factors in the matter of motivation for managers and supervisors is completely applicable (Moghimi, 2009). Additionally, these results agree with results of Alvijeh (2013) based on a relationship between organizational culture and job motivation among primary school teachers.

2- What is the situation of organizational culture among education and development employees of the counties of Semnan?

Considering the results, organizational culture among employees of offices of education and development in the counties of Semnan is higher than average. These results agree with findings by Gholami (2011). In evaluation of organizational culture of counselors of the country of Tehran, this researcher has reported the situation of organizational culture as appropriate and has noted that no difference exists between organizational culture among male and female counselors. Yet, a humane centered atmosphere creates a high level of performance and satisfaction along with it and it requires consideration of humans and needs in factors constituting organizational culture (Parsons, 2000).

3- What is the situation of motivation among education and development employees in the counties of Semnan? Results showed that the situation of job motivation among employees of offices of education and development in counties of Semnan is higher than average. These results agree with findings of Nasirzadeh (1999), Nayeri (2000) and Chen (2007) and disagrees with results of Gholami (2011). This researcher has also reported job motivation in female counselors to be higher than male counterparts who might be due to higher interest in financial independence and management in women.

4- Is there a relationship between constituents of organizational culture (job challenge, communication, innovation, trust and social connectedness) with job motivation among education and development employees of the counties of Semnan?

Results showed that constituents of organizational culture explain 19 percent of the variance of job motivation. These results agree with findings of Davoudi (2012) who has shown in his research that the variables of job motivation, organizational culture and age meaningfully predict work satisfaction. Constituents of job motivation are meaningful predicting variables for constituents of organizational culture and work satisfaction. Also, our findings agree with the research by Ghafori (2008) who has reported that the most important trait of organizations with weak culture is that the hierarchy of discretions travel in vertical direction and almost all power is centered at higher ranks in the organization. Also, these results agree with findings of Ismyarto (2015) based on a positive and meaningful relationship between constituents of organizational culture with job motivation.

5- Is there a relationship between constituents of job motivation (skills' diversity, value of duty, and feedback from supervisor, meaningful duties and independence) with organizational culture among education and development employees of the counties of Semnan?

Considering the results, it can be stated that with increased organizational culture, all constituents of job motivation in employees of offices of education and development of the counties of Semnan are increased and the reverse. Mehmet D and colleagues (2009) performed a study titled "Effect of motivation on job satisfaction and organizational commitment of teachers" the results of which showed that motivation has positive effect on organizational commitment and job satisfaction and high motivation brings along with it increased job satisfaction and low motivation decreases job satisfaction. Additionally, job satisfaction influences organizational commitment and teachers who have high job satisfaction, possess higher organizational commitment and culture.

This conclusion agrees with reported findings by Lin (2005), Stanley (2005), Frisko (2005) and also Hamermasitter (2005). Zareimatin (1991) also while explaining a model for organizational culture based on Islamic values at the work place shows its role in job satisfaction. In organizations that are in better conditions with regards to the ideal organizational culture, job satisfaction and motivation are also higher.

6- Is there relationship between organizational culture with motivation and work experience of education and development employees in the counties of Semnan?

Considering the results obtained, it can be stated that remaining variables in the regression explain 20 percent of the variance of job motivation among employees of offices of education and development of the counties of Semnan province. 
Marlin L and colleagues (2010) in a research titled "Effect of motivation in job satisfaction of directors" have shown that directors with long work experience in executive management and who have greatly collaborated with nursing universities and schools have shown direct correlation between their motivation and job satisfaction. Additionally, motivation is an important predictor of job satisfaction.

With consideration of the necessary importance of appropriate organizational culture and its role in promotion of office system standards for employees, it is suggested that educational programs during service are emphasized and trainings appropriate with the topic are provided by the center of educational studies for human resources for established personnel. Additionally, considering the importance of effects of organizational cultural system on various office and educational sectors, it is suggested that people influenced by organizational culture are acknowledged in records and are granted awards and facilities to encourage them and receive promotion at work.

\section{Suggestions}

- Considering the relationship between organizational culture and job motivation among office employees of education and development departments, it is suggested that workshops are held for promotion of organizational culture and job motivation.

- Considering the relationship between constituents of organizational culture and job motivation, it is suggested that journal and books are acquired and placed in reach of employees to promote and increase these skills.

- During service educational programs are also recommended for promotion of office system standards and increasing motivation.

- Considering the relationship between work experience and job motivation, it is suggested that with attention to endeavors and innovations of personnel, encouragement and facilities are granted to them with the purpose of better service quality.

\section{References}

[In Persian]

Moghimi, Seyed Mohammad; Ramezan, Majid (2011). Management Journal, cover eleven. Tehran: Rahdan Publications.

[In Latin]

Belias, B(2014), Organizational Culture and Job Satisfaction: A Review, International Review of Management and Marketing. Vol. 4, No. 2, 2014, pp. 132-149. ISSN: 2146-4405

Frisko, Amitai.(2005),"Modern Organizations". New Jersey:Prentice-Hall.

Ghafori Varsofaderani MR.(2008) Investigating relationship between psychological climate with psychological empowerment and job control in manufacturing plant in Isfahan [Dissertation]. Ahvaz: Shahid Chamran University; 2008. [Persian]

Ismiyarto Ismiyarto, Sri Suwitri, Y. Warella, Sundarso Sundarso .(2015). Organizational Culture, Motivation, Job Satisfaction and Performance of Employees toward the Implementation of Internal Bureaucracy Reform in the Ministry for the Empowerment of State Apparatus and Bureaucracy Reform (The Ministry of PANRB). DOI: 10.5539/jms.v5n1p192

Julia sehuler. Kennon m, Sheldon. stephanie m. froblich.(2010). Implicit need for achievement moderetes the relationship between competence need satisfaction and subsequent motivation. vol (44). Lss 1.p.p (1-12).

Lin, J, and Henry L.Tosi.(2005)," Management by objectives:Applications and Research", New York: The Macmillan company, - Stanly, Andrew J.,

Marcoulided, G. A., Heck, R. H. (2009). Organizational culture and performance, proposing and testing amodel. Organization science vol (4), Iss2.

Marlin I. lamborn R N. (2010). Motivation and job satisfaction of school of nursing. Voll (5). Iss 1

Marlin I. lamborn R N. (2010). Motivation and job satisfaction of school of nursing. Voll (5). Iss 1.

Mehmet D. karsli \& Hale iskendar. (2009). To examine the effect of the motivation provided by the administration on the job satisfaction of teachers and their institutional commitment. Vol (7). p. p. (33-40).

Owoyemi O,Ekwoaba J.O.(2014). Organizational Culture: A Tool for Management to Control, Motivate and Enhance Employees' Performance. American Journal of Business and Management Vol. 3, No. 3, 2014, 168-177 DOI: 10.11634/216796061403514 